\title{
Social-cultural impacts of China-Pakistan Economic Corridor on the well-being of local community
}

\author{
Yunpeng Sun (corresponding author) \\ School of Economics \\ Tianjin University of Commerce \\ tjwade3@126.com
}

\author{
Abdul Hameed Pitafi (corresponding \\ author) \\ School of Management \\ Hefei University of Technolog China \\ hameedpitafi@hotmail.com
}

\author{
Usman Ghani \\ School of Education \\ Zhejiang University China \\ gusman@mail.ustc.edu.cn
}

Tahir Islam (corresponding author)

School of Economics and Management

Tongji University

kktahir@hotmail.com

\begin{abstract}
In this research, the impact of infrastructure improvement as a result of the China-Pakistan Economic Corridor (CPEC) initiative on the well-being and quality of life (QOL) of residents has been studied. Using the primary data collected from the local population of the Baluchistan province of Pakistan, a link between the socio-cultural effects of CPEC development and the subjective well-being of local citizens has been established. A total of 495 relevant responses were used to assess the well-being of the population through structural equation modeling. Results have shown that the social, cultural, and educational benefits of local communities are significant predictors of the wellbeing of citizens, and QOL issues have shown to have a major impact on the well-being of citizens. However, findings have also shown that the community resource has an important link with the subjective wellbeing of citizens. Furthermore, the results also give the local community perceptions of the CPEC initiative; hence the officials of the province can use the findings of this study to create prospective approaches based on the local community perceptions toward better exploitation of CPEC as an opportunity.
\end{abstract}

Keywords: CPEC, well-being, education, social-cultural, quality of life, community resource

\section{Introduction}

Residence Quality of Life (QOL) has been extensively discussed by past academics and evaluated using distinct parameters, including the subjective well-being of citizens (Kim, Uysal, \& Sirgy, 2013; Yolal, Gursoy, Uysal, Kim, \& Karacaoğlu, 2016). Yolal et

\section{Article history:}

Received: January 24, 2020

Received in revised form:

June 8, 2020

Accepted: September 29, 2020

Available online: November 17, 2020

Copyright 2020 Yunpeng Sun, Usman Ghani, Abdul Hameed Pitafi \& Tahir Islam http://dx.doi.org/10.5198/jtlu.2020.1724

ISSN: 1938-7849 | Licensed under the Creative Commons Attribution - Noncommercial License 4.0

The Journal of Transport and Land Use is the official journal of the World Society for Transport and Land Use (WSTLUR) and is published and sponsored by the University of Minnesota Center for Transportation Studies. 
al. (2016) proposed that resident's subjective well-being is a key element of overall QOL. Subjective wellbeing is therefore described as an individual's cognitive and emotional evaluation of his/her life (Diener \& Suh, 1997). Cognitive assessment is linked to an individual's perception of how a development plan can improve its life satisfaction; affective assessment is linked to the individual reaction and emotions connected with development projects (Diener, Oishi, \& Lucas, 2003). Pakistan is an underdeveloped country and QOL's local living is below average. The Pakistani government is continually developing strategies and imitating development initiatives that improve the well-being of citizens. China-Pakistan Economic Corridor (CPEC) is a main initiative among several initiatives that help the local society in many ways. For instance, the CPEC development project will provide the fundamental animators of life, including schooling, jobs and easy access to major towns and markets (Kanwal, Chong, \& Pitafi, 2019a). Scholars and leaders also argue that the CPEC will increase local community living standards by offering evolving possibilities for exploitations (Ali, Mi, Shah, Khan, \& Imran, 2017; Kanwal, Chong, \& Pitafi, 2019b). In addition, past research also observed that the well-being of residents can be developed through many development projects (Kanwal, Pitafi, Pitafi, et al., 2019; Woo, Kim, \& Uysal, 2015). This is to name a few studies, whereas the benefits are numerous, but research studies related to local community living standard and CPEC development are very limited (Ali et al., 2017; Kanwal et al., 2019b). Specifically, Ali et al. (2017) asserted that the CPEC road and transport project could improve the living standards of local communities by offering them global connectivity. Kanwal et al. (2019a) reported that the construction of CPEC infrastructure could boost local community revenue by offering them educational, business, and employment opportunities that transform into QOL enhancements. Although these studies are well organized generally but are restricted to the benefits of CPEC. This research, therefore, investigated the effect of CPEC development on the well-being of citizens as considerably Baluchistan province is a significantly deprived area of the Pakistan but very rich in mineral resources hence the rich resources theory is evidently perfectly applied.

Recently, studies related to the well-being of inhabitants have received scholarly attention in a variety of fields. In this regard, scholars noted that the objective of modern societies is to enhance the well-being of citizens and these studies have proposed several factors (Chen, Lehto, \& Cai, 2013). Among other factors, the actions of citizens that improve social interactions are substantially linked to well-being (Yolal et al., 2016). Social interactions improve the well-being of people by enabling them to develop a feeling of belonging and decreasing depression (Cohen, 2004). Some scholars reported that CPEC will enhance social interaction among the communities (Ali et al., 2017; Hussain, 2017; Kanwal, Pitafi, Rasheed, Pitafi, \& Iqbal, 2019). The development of CPEC not only improves the economy of locals but also benefits the society from a socio-cultural point of view. For example, access to educational institutions, health facilities, employment, business possibilities, and interactions between local communities by facilitating social activities (Kanwal et al., 2019b; Kanwal, Pitafi, Malik, Khan, \& Rashid, 2020). Asomani-Boateng, Fricano, and Adarkwa (2015) proposed that it would be easy for individuals to meet their friends and families with road and transport infrastructure development. Previous studies have examined the role of socio-cultural impacts on local communities' well-being through festivals and tourism development (Nawijn \& Mitas, 2012; Yolal et al., 2016), whereas CPEC in general has been widely overlooked. This study will cover this specific research gap by focusing mainly on investigating the inhabitant's views of CPEC's socio-cultural impacts on their subjective well-being. By evaluating subjective well-being as an outcome construct, results will allow us to identify the magnitude and orientation of the relationship between socio-cultural effects and the subjective well-being of inhabitants. We are therefore investigating the well-being of citizens through social interaction in the framework of CPEC development, as CPEC although an opportunity brings with it many challenges as well.

Although CPEC can improve the subjective well-being of local inhabitants, we have little knowledge of how CPEC can favorably affect the subjective well-being of citizens and their standard of lives. 
The aim of this research is, therefore, to examine how developments in CPEC can affect their subjective well-being and standard of lives by concentrating on the relationship between the socio-cultural effects of CPEC and the well-being of citizens. More specifically, this research intends to assess the connection between inhabitants' perceptions of the socio-cultural impacts of community benefits, cultural/ educational benefits, QOL concerns, and community resource concerns and their well-being in the framework of CPEC. The results of this study are will attempt to make relative contributions to theoretical literature by furthering our knowledge of things that may influence the subjective well-being of individuals and their QOL in a number of ways. Firstly, according to best of the author's understanding, the present research is the first survey centered on the well-being of citizens in the framework of CPEC. Previously, scholars explored the subjective well-being of residents in the context of festival and tourism development (Yolal et al., 2016). Secondly, present research highlighted the social cost and benefit of CPEC infrastructure development and its effect on the subjective well-being of residents. Third, the current study also provides awareness among residents of Baluchistan Province of Pakistan related to $\mathrm{CPEC}$ project by highlighting the social and educational benefits of CPEC and its positive impact on infrastructure development.

\section{$2 \quad$ Literature review and hypotheses development}

\subsection{Impact of CPEC infrastructure}

CPEC includes a wide range of development areas, such as economic development, regional connectivity projects, manufacturing zones, and infrastructure projects, that are currently underway in Pakistan (Kanwal et al., 2019a). The CPEC project in Pakistan covers most of the areas of Pakistan such as started from Gwadar, Balochistan and connecting all the provinces (Punjab, Sindh, Balochistan, and Khyber Pakhtunkhwa), finally ends at the Khunjarab region, border of Pakistan and China (Kanwal et al., 2019b). The CPEC was launched by Chinese President Xi Jinping in April 2015, with a complete expenditure of $\$ 46$ billion in Pakistan (Ahmad \& Hong, 2017; Kanwal, Pitafi, Rasheed, et al., 2019). Officials from both nations suggesting that the smooth execution of the CPEC project will alter the shape of the entire region. With the construction of this mega-project, Pakistan will resolve its energy, and economic crisis, while China needs the safest and easiest route for oil transport, dubbed the win-win solution. Currently, $83 \%$ of Chinese petroleum is exported through the Malacca Strait (Kanwal et al., 2019a), which is a very long route. Moreover, China's policymakers know Malacca's Strait as a danger route in the long-term and not good for business, as this Strait is under American control and the recent times has seen the relationship between the two superpowers become volatile. (Ali et al., 2017). CPEC will, therefore, become the simplest and safest path, which will also reduce shipping costs and shipment time to China (Shaikh, Ji, \& Fan, 2016).

According to the evaluation of the CPEC route, Gwadar port in Baluchistan will soon become a business center as it will connect the Middle East directly with the largest populated country in the world. Several CPEC projects have already completed and some are expected to be completed in the near future. For instance, lately, under the title of the CPEC initiative, a girl's college was built in this remote rural area of Pakistan, benefiting the local society of Gwadar (Kanwal et al., 2019a). Despite several benefits of the CPEC project, researchers also observed some adverse impacts of the CPEC route, such as traffic congestion, noise, environmental issues and the devastation of agricultural land (Kanwal et al., 2019a; Kanwal, Pitafi, Rasheed, et al., 2019). As a result, present study sheds light on the socio-cultural effect of the CPEC route and its connection with the well-being of citizens. 


\subsection{Subjective well-being of residents}

Subjective well-being is described as "the cognitive and emotional assessment of a person's life" (Diener $\&$ Suh, 1997). Whereas cognitive assessment relates to a person's specific assessment of the effect of a case on his or her life satisfaction, emotional evaluation takes into consideration the emotions, feelings and attitudes that activity may produce. As a result, subjective well-being can also be described as the result of a person's emotional response to occurrences and their cognitive evaluation of the satisfaction that gives life satisfaction through these occurrences. Subjective well-being involves an individual's emotional and cognitive evaluation of his/her life, as well as his/her conceptualization of happiness, enjoyment, and life satisfaction (Diener et al., 2003). In addition, subjective well-being has a significant part to play in personal lives in attempt to attain its greatest operating capability, full of trust in the achievement of important objectives and has the incentive and authority to continually solve obstacles in the cycle of life.

Research in psychology has already given us the fundamental demands of human beings are met when they are given constant well-being (Ryan \& Frederick, 1997). Naidoo and Pearce (2018) found a positive relation of tourism development and involvement in tourism to well-being. CPEC can offer such an opportunity to the local community, to utilize it and satisfy their needs. These possibilities include social benefits, educational /cultural advantages, and improving the living standards of the local society, can make a positive contribution to the well-being of locals by fulfilling their requirements. Similarly, there are some issues of the local society that may have a negative impact on the well-being of the local society, such as resource issues. For instance, in CPEC development projects, the rich assets of the local society, such as property damage and land repossession (Kanwal et al., 2019b; Rehman, Hakim, Khan, \& Khan, 2018), may have a negative impact on the subjective well-being of the locals. Therefore, it is interesting to investigate the positive and negative effects of CPEC projects on the subjective well-being of the local society.

\subsection{Community benefits, subjective well-being}

The Community benefits are elaborated in the context of any developmental activity for society in order to build an image, to show others the unique characteristics, to improve life, and to share information/ ideas of the local community (Yolal et al., 2016). Various factors add to the benefits of the local society. For instance, tourism development performs a key part in the development and enhancement of the lives of the local community (Daldeniz \& Hampton, 2013). Likewise, cultural events provide a chance for distinct ethnic groups to communicate their culture and distinctive features of their society (Yolal et al., 2016). In addition, development projects are the tools for a group to construct their picture, act as an animator and promoter of social and economic development to attract investors, sponsors and tourists (Quinn, 2006; Richards \& Wilson, 2004). However, such possibilities (e.g. tourism) still rely to a large extent on the development of infrastructure, because it makes it more convenient for promoters, tourists, and shareholders to reach distant areas (Kanwal, Rasheed, Pitafi, Pitafi, \& Ren, 2020). Hence it is expected that infrastructure development will have been accomplished by the completion of CPEC (Kanwal, Pitafi, Rasheed, et al., 2019).

Under CPEC, 27 economic zones will be developed across the country (Kanwal, Pitafi, Rasheed, et al., 2019), which will enhance job opportunities and improve the living standards of the local society, especially in the underdeveloped areas of both nations. Dost Muhammad Khan Chairman of Gwadar Port Authority said that only Gwadar port provided about 40,000 employment vacancies (Kanwal et al., 2019a). CPEC is therefore considered to be a game-changer for Pakistan's economy and local communities because this will improve the skills and capabilities of local communities by exchanging ideas with the foreigners and by promoting the picture of their communities as people of peace and prosperity. 
In addition, researchers and CPEC authorities state that the economic sustainability of local communities in Pakistan will improve as CPEC projects develop (Ali et al., 2017; Kanwal et al., 2019a) because $\mathrm{CPEC}$ offers many possibilities for local communities to carry out business. Accordingly, local communities can begin small industries, hotels, workshops, and establish agricultural projects across the CPEC route (Kanwal, Pitafi, Rasheed, et al., 2019). Previous discussions indicate that CPEC builds a strong tie with the local community and enhances community welfare that may affect residents' subjective wellbeing. Hence, the following assumptions are suggested:

H1. There is a positive relationship between residents' perception of community benefits with the development of CPEC and their subjective well-being.

\subsection{Educational/cultural benefits, subjective well-being}

The educational /cultural advantages of development projects are elaborated by Yolal et al. (2016), states that new learning possibilities, new thoughts, exposure of inhabitants to distinct social backgrounds, and leisure possibilities for the local society. Existing literature shows that CPEC provides many possibilities for educational and economic development (Kanwal, Pitafi, Rasheed, et al., 2019). Previous surveys have shown that infrastructure development has an important effect on local community enrolment in education (Asomani-Boateng et al., 2015). Developed infrastructure system reduces the cost and time to access the educational institutes. For instance, Haq and Farooq (2016) stated that one of the prime reasons for underdeveloped areas is low literacy level due to the limited number of schools and the location of colleges from the local communities. Similarly, Mattson (2011) discovered that the affiliation of long-distance travelers had a serious adverse effect on the literacy level of the local community. Smith (2001) suggested that, with the completion of CPEC, the distance between the educational institutions and the local communities would be reduced.

Moreover, Chinese and Pakistani officials are expecting that the establishment of a special zone of information technology, and education industries will help to upgrade the performance of education in the region (Barrios, 2008). For example, the Panjab-Jiangsu Cultural Center (PJCC) is part of the CPEC initiative between the National University of Modern Languages (NUML) of Pakistan and the Chinese Xinjiang Normal University, which provides a platform for understanding culture and improving the quality of education in the region. Similarly, the CPEC route will improve people's communication with individuals, this will promote culture, make it easy for citizens to meet their friends, families and bring the part in various social activities (Kanwal, Pitafi, Ahmad, et al., 2019), which will also give unique identification to the area.

Previous debates indicate that CPEC offers several educational/cultural possibilities that would give various advantages to both residents and tourists and that these possibilities and advantages are probable to have an important beneficial effect on the subjective well-being of both residents and tourists. Based on the above discussion, we propose the following hypothesis:

$\mathrm{H} 2$. There is a significant link between residents' perception of cultural/educational benefits with the development of CPEC and their subjective well-being.

\subsection{Quality of life (QOL) concerns, subjective well-being}

QOL has been described as the well-being, enjoyment, and satisfaction of the individual from life itself (Sirgy, Rahtz, Cicic, \& Underwood, 2000). The notion of QOL is conceptualized as whether people have a pleasant lifestyle or a poor lifestyle (Diener et al., 2003). The construct of QOL termed as an 
umbrella, which is used interchangeably with life satisfaction (Kanwal, Pitafi, Rasheed, et al., 2019; McGillivray \& Clarke, 2006). Many studies have also reiterated that the infrastructure development has rendered it easier to achieve a tourism easily (Masson \& Petiot, 2009).

Although development projects have some beneficial effects on the lives of local communities, they also have adverse implications such as noise pollution, increased living costs, property damage, and crime (Kanwal, Pitafi, Rasheed, et al., 2019). CPEC can also cause negative influences on the natural and physical environment. For example, with infrastructure development, new businesses and industrial zones will also develop. Previous literature demonstrates that such sectors trigger pollution of water, air, and noise, and destroy the natural environment (Kanwal et al., 2019b). Another important cost is the accumulations of solid waste produced by the manufacturing plants in sub-urban regions, where the disposal is reused and air quality is harmed and can trigger environmental problems in the local region. Hence, we propose that:

H3. There is a negative link between the perceived concerns of CPEC development to residents' QOL concerns and their subjective well-being.

\subsection{Community resource concerns, subjective well-being}

It is recognized that the construction of the mega-project requires a significant investment of human and physical resources from local groups (Pappas, 2014). Considering that host community support is essential for the smooth development of the project is an important element for its success, a lack of communication and collaboration from the local community may cause the planning process to be challenged (Yolal et al., 2016). The extent to which funds are used for development may lead to some adverse effect on stack owners. Specifically, a higher level of development is likely to utilize higher local assets and their levels of depletion. Scholars noted that local communities are opposed to the development project because they think that the personal and economic benefits may not justify the expenses of the development project (Pappas, 2014; Yolal et al., 2016). The researcher also noted that local groups believe that construction projects can have more adverse effects than beneficial ones on their societies, such as resource mismanagement, extra tax burdens (Nunkoo \& Gursoy, 2016). Consequently, the amount of adverse and beneficial views expressed on the effective or inefficient use of funds may interrupt the required amount of QOL in society.

Like other development projects, CPEC development also needs several assets at the local stage. For instance, the design of the Gwadar port has moved to the local community residing alongside the port. In addition, the indigenous population of the Gwadar region is connected with fishing trade, with the construction of a port locals are therefore unable to capture fish more than 20 kilometers in the ocean, and this change creates an unwanted nuisance for the officials if not properly handled (Kanwal et al., 2019a; Wolf, 2018). Past study indicate that the local Baloch group is not favored in the development of the Gwadar port, as they understand that the development of Gwadar is a means of continuous usage of their rich asset (Kanwal, Chong, et al., 2019b; Rehman et al., 2018). For instance, the removal of local communities from their homes, land repossession, property damage, and environmental impact induced by developments in the CPEC are creating more conflicts. Additionally, the current property prices of the city of Gwadar are very low, with the development of the modern city of Gwadar and the port, the property prices will be enormous in the region and beyond the reach of many locals. As a consequence, the local inhabitants will not be able to afford to purchase land in their own town. Currently, several Chinese and other Pakistani people have settled in the Gwadar region. Past literature proposed that if residents are concerned that the way resources are used and consumed to for development 
projects, may decrease their QOL, they may oppose the concept of development within their region. Therefore, this research hypothesis that:

H4: There is a negative link between residents' perception of community resource concerns with the development of CPEC and their subjective well-being.

\section{Research methods}

\subsection{Study site}

Data were gathered from the province of Baluchistan, Pakistan. Baluchistan province is a rich province of Pakistan in terms of natural resources. However, given the absence of infrastructure development and awareness in the local society, this province is a backward region of Pakistan. The major project of $\mathrm{CPEC}$ is Gwadar port and development of city Gwadar, education institutes, and industrial zones. The author selected the Baluchistan province for this study for several reasons. First, according to authorities, the CPEC initiative is more useful to the Baluchistan province of Pakistan than to other provinces. The development of the Gwadar port and Gwadar city will benefit the local society. Second, the Baluchistan province of Pakistan is a backward province of Pakistan, and the CPEC scheme is expected to change the fortunes of the entire Baloch communities. Third, the Baloch group of Pakistan is opposed to the development of the CPEC initiative due to several political and social issues. Fourth, some CPEC projects are already operationalized in Gwadar city such as educational institutes, health centers, Gwadar international airport, and transportation infrastructure.

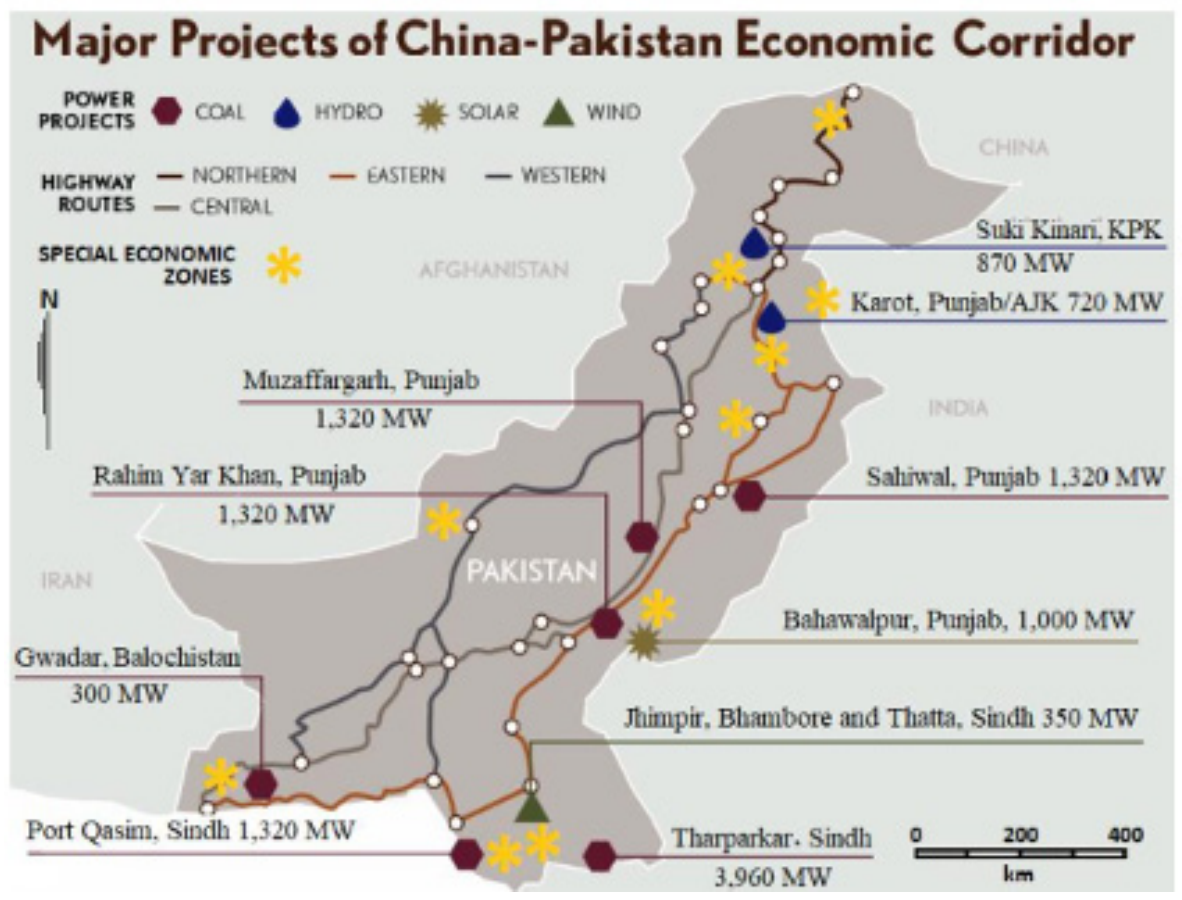

Figure 1. Map indicating major projects of CPEC. Source (Farooqui \& Aftab, 2018). 


\subsection{Data collection procedure}

In order to evaluate the research model of this study, a survey technique was used for data collection. The target population of this research is the Baloch community residing in distinct cities of Baluchistan, such as Quetta and Gwadar. The author was assisted by five indigenous Baloch people in the data collection process. With the help of the native residence, the author first held meetings with the local community, this was facilitated by the fact that the lead author belongs to a Baloch tribe himself, and discussed the benefits and costs of CPEC projects and their impact on their lives. The entire questionnaire was first designed in English and then converted into Urdu language. For a clear understanding of local residence, the questionnaire comprises of languages such as English and Urdu. First, the author conducted a pilot survey of sixty-five samples, and the findings were discovered to be adequate and these sixty-five samples were deleted from the final data collection. We used a random sampling method and circulated 600 questionnaires in printed format to different areas of Baluchistan, along with small gift items and received 490 completed questionnaires with a response frequency of $70 \%$. Past studies recommended a random sample approach when samples have distinct characteristics and have less available information (Boschini, Dreber, von Essen, Muren, \& Ranehill, 2018; Chaum, 2019).

After assessing the received questionnaires, the ones with incorrect responses or an unfinished questionnaire were excluded, the final tally was 395 samples. Demographic information for all samples is shown in Table 1 . Table 1 illustrates that $70 \%$ of the participants were a male and $30 \%$ female respondents. The respondents to this research were concerned with distinct occupations of distinct age groups. All participants were notified that their response would be kept confidential, and anonymity was maintained, and they were further informed that the data would only be used for study purposes.

Table 1. Demographic information of the samples

\begin{tabular}{|c|c|c|}
\hline & $\mathbf{N}$ & Percentage \\
\hline \multicolumn{3}{|l|}{ Gender } \\
\hline Male & 324 & 65.5 \\
\hline Female & 171 & 34.5 \\
\hline \multicolumn{3}{|l|}{ Age } \\
\hline $21-30$ years old & 173 & 34.9 \\
\hline $31-40$ years old & 156 & 31.5 \\
\hline $41-50$ years old & 166 & 33.5 \\
\hline \multicolumn{3}{|l|}{ Education level } \\
\hline Bachelors/Undergraduate & 201 & 40.6 \\
\hline Masters/Graduate & 232 & 46.9 \\
\hline Doctoral Degree & 62 & 12.5 \\
\hline \multicolumn{3}{|l|}{ Income } \\
\hline 5000 to 10000 Rupees & 45 & 9.10 \\
\hline 11000 to 20000 Rupees & 199 & 40.2 \\
\hline 21000 to 30000 Rupees & 119 & 24.0 \\
\hline Higher than 300000 Rupees & 132 & 26.7 \\
\hline \multicolumn{3}{|l|}{ Marital Status } \\
\hline Married & 371 & 74.9 \\
\hline Un-Married & 124 & 25.1 \\
\hline \multicolumn{3}{|l|}{ Occupation } \\
\hline Student & 116 & 23.4 \\
\hline Government Employment & 146 & 29.5 \\
\hline Private Employment & 120 & 24.2 \\
\hline Self-Employment & 113 & 22.8 \\
\hline
\end{tabular}




\subsection{Survey measurement}

The survey measurement of the current study have been adopted from previous literature, which is already published in well-known journals of repute (Delamere, Wankel, \& Hinch, 2001; Yolal et al., 2016). All the instruments were measured using 5-point Likert-Scale from "Strongly Agree" to "Strongly Disagree," as 5-point Likert-Scale widely used by previous scholars (Pitafi, Khan, Khan, \& Ren, 2020; Wei, Pitafi, Kanwal, Ali, \& Ren, 2020). The research model of the study comprises of two parts such as social benefits and social costs. Social benefits included community benefits and educational/cultural benefits of the local community related to the development of CPEC, while social costs included QOL concerns and community resource concerns. The dependent variable subjective well-being of residents was investigated using social benefits and social costs. The contents of all the items have been modified according to the study context. The detail of each measurement items is shown in appendix A.

\subsection{Subjective well-being}

Subjective well-being is defined as overall evaluations of one's satisfaction with general and specific areas of one's life. In the context of CPEC, subjective well-being measures the individual satisfaction or evaluation associated with CPEC infrastructure development. The scale of subjective well-being consists of total of three items. The instrument of subjective well-being was adopted from Yolal et al. (2016).

\subsection{Community benefits}

The measurement instrument of community benefits measures overall local community benefits related to CPEC project. Total four items were used to measure the community benefits and scale adopted by (Delamere et al., 2001; Yolal et al., 2016). In this study, the community benefits are defined as benefits received by entire community with the development of CPEC infrastructure.

\subsection{Cultural/educational}

To measure the scale of cultural/educational benefits of residents related to CPEC, the following scale was used (Delamere et al., 2001; Yolal et al., 2016). The construct of cultural/educational benefits consists of four items. The construct of cultural/educational benefits consisted of items, which measure the cultural/educational benefits with the development of CPEC infrastructure development including education institutes, training centers, and road infrastructure.

\subsection{Quality of life concerns}

To measure the QOL concerns of local community four items were used (Delamere et al., 2001; Yolal et al., 2016). The QOL related items of measure for local community, and QOL with the development of CPEC project. QOL refers to an individual's well-being, happiness and life satisfaction. 


\subsection{Community resource concerns}

The scale of community resource concerns was measured using (Delamere et al., 2001; Yolal et al., 2016). The scale consists four items in total and measures the local community perception related to community resource. In the context of CPEC, community resource concerns measure the local community resource, which was utilized in the development of CPEC infrastructure development such as damage of property, water and agriculture land.

\subsection{Control variable}

To assess the real impact of social cost and social benefits related to CPEC on subjective well-being, resident's age, education, gender, occupation was used as a control variable.

\section{$4 \quad$ Data analysis}

\subsection{Measurement model}

This study's measurement model was explored using the method of confirmatory factor analysis (CFA). CFA's aim is to evaluate the model fit requirements (Hair, Ringle, \& Sarstedt, 2011; Pitafi, Kanwal, \& Pitafi, 2019). First, before evaluating the overall measurement model, each model variable was evaluated individually. Each research variable was re-specified after the error variances, loadings, and modification indicators. Results of this method indicated 5 values for community benefits, 4 values for cultural/educational benefits, 4 values for QOL concerns, 4 values for community resource concerns, and 3 values for subjective well-being of residents. Finally, the measurement model was examined and the results of the measurement model $(\mathrm{CFI}=0.959, \mathrm{TLI}=0.952, \mathrm{IFI}=0.952, \mathrm{NFI}=0.934, \mathrm{AGFI}=0.902, \mathrm{REMSA}$ $=0.05, \mathrm{CMIN} / \mathrm{DF}=445.94 / 174=2.49)$ indicate that the values are within the standard range and that the research model is acceptable (Hair, Hollingsworth, Randolph, \& Chong, 2017).

In addition, the convergent validity and design of the research model were evaluated using several tests. We examined the factor loading, Composite reliability (CR), average variance extracted (AVE) and Cronbach's alpha (CA) for each construct. As indicated in Table 2, the loading of each item were > 0.6, which is the minimum threshold value as indicated (Fornell \& Larcker, 1981). CR and CA scores are appropriate if they are greater than 0.70 (Nunnally \& Bernstein, 1978). The results shown in Table 2 stated that $\mathrm{CR}$ scores vary from (0.89 to 0.96$)$ and CA from (0.83 to 0.94$)$ which are appropriate. Hinkin (1998) suggested that AVE scores should be $>0.50$. The results shown in Table 2 indicated that all AVE values are within the range ( 0.67 to 0.87 ) which are within the standard range. These findings validated the appropriate convergent validity of the research model. 
Table 2. CFA results

\begin{tabular}{|c|c|c|c|c|c|}
\hline Construct Name & Items & Loadings & CA & CR & AVE \\
\hline \multirow[t]{4}{*}{ Cultural/educational benefits } & EC1 & 0.804 & 0.834 & 0.89 & 0.67 \\
\hline & $\mathrm{EC} 2$ & 0.884 & & & \\
\hline & EC3 & 0.764 & & & \\
\hline & EC4 & 0.809 & & & \\
\hline \multirow[t]{4}{*}{ Community Benefit } & CB1 & 0.795 & 0.842 & 0.89 & 0.68 \\
\hline & $\mathrm{CB} 2$ & 0.852 & & & \\
\hline & CB3 & 0.861 & & & \\
\hline & CB4 & 0.788 & & & \\
\hline \multirow[t]{4}{*}{ Quality of Life Concern } & QOL1 & 0.921 & 0.879 & 0.92 & 0.72 \\
\hline & QOL2 & 0.709 & & & \\
\hline & QOL3 & 0.893 & & & \\
\hline & QOL4 & 0.888 & & & \\
\hline \multirow[t]{4}{*}{ Community Resource Concerns } & CR1 & 0.906 & 0.946 & 0.96 & 0.86 \\
\hline & CR2 & 0.935 & & & \\
\hline & CR3 & 0.943 & & & \\
\hline & CR04 & 0.925 & & & \\
\hline \multirow[t]{3}{*}{ Subjective well-being of Residence } & SWB1 & 0.873 & 0.855 & 0.91 & 0.77 \\
\hline & SWB2 & 0.886 & & & \\
\hline & SWB3 & 0.869 & & & \\
\hline
\end{tabular}

Note: Items: = no of items used in constructs, Loadings: = Factor Loading, CA = Cronbach's alpha; CR = composite reliability; $\mathrm{AVE}=$ average variance extracted,

Scholars suggested several procedures to analyze the discernment validity of the research model (Liu, Ke, Wei, \& Hua, 2013; Pitafi, Liu, \& Cai, 2018; Pitafi, Rasheed, Kanwal, \& Ren, 2020). In this, we follow the procedure of (Liu et al., 2013) to confirm the discernment validity of the research model. According to this procedure, we compared the AVE square root with the inter-correlation of each variable. As indicated in Table 3, all AVE square roots were higher than the inter-correlation, which demonstrates that the research model has an appropriate level of discernment validity.

Table 3. Correlations and descriptive statistics

\begin{tabular}{|c|c|c|c|c|c|c|c|c|c|c|c|c|}
\hline Construct & $\mathbf{M}$ & SD & 1 & 2 & 3 & 4 & 5 & 6 & 7 & 8 & 9 & 10 \\
\hline 1. Cultural/educational benefits & 4.03 & 0.88 & 0.81 & & & & & & & & & \\
\hline 2. Community Benefit & 4.13 & 0.91 & 0.20 & 0.82 & & & & & & & & \\
\hline 3. Quality of Life Concern & 3.35 & 1.16 & 0.05 & 0.06 & 0.84 & & & & & & & \\
\hline 4. Community Resource Concerns & 2.51 & 1.00 & -0.12 & 0.04 & -0.07 & 0.92 & & & & & & \\
\hline 5. Subjective well-being of Residence & 4.01 & 0.73 & 0.18 & 0.16 & 0.08 & 0.11 & 0.87 & & & & & \\
\hline 6. Occupation & NA & NA & -0.07 & -0.08 & 0.07 & -0.15 & -0.07 & NA & & & & \\
\hline 7. Income & NA & NA & -0.10 & -0.04 & -0.07 & -0.02 & 0.02 & 0.02 & NA & & & \\
\hline 8. Education level & NA & NA & -0.01 & 0.15 & -0.13 & 0.08 & 0.08 & -0.08 & 0.06 & NA & & \\
\hline 9. Age & NA & NA & -0.09 & -0.01 & -0.01 & 0.11 & -0.07 & 0.01 & 0.11 & 0.08 & NA & \\
\hline 10. Gender & NA & NA & -0.12 & -0.16 & -0.09 & 0.01 & -.010 & 0.02 & 0.07 & -0.06 & -0.07 & NA \\
\hline
\end{tabular}

Note: $\mathrm{M}=$ mean; $\mathrm{SD}=$ standard deviation. The diagonal elements are the square root of the AVE. 
Together with validity and reliability, we also evaluated multicollinearity in order to assess the potential problem of multicollinearity in the data set (Cohen, Cohen, West, \& Aiken, 2013; Fornell \& Larcker, 1981; Pitafi, Kanwal, Ali, Khan, \& Ameen, 2018). Cohen et al. (2013), argued that there is not a serious issue of multicollinearity in the data set if VIF values are less than 10 . The findings stated that the VIF scores varied from (0.5-2.10). Thus, multicollinearity is not a serious problem for this research.

In addition, considering that data is collected using the same processes, each respondent responded to all study questionnaires, and the extent of common method variance (CMV) was examined using two distinct processes. First, CMV was evaluated using processes suggested by Liang, Saraf, $\mathrm{Hu}$, and Xue (2007). The findings of this assessment have shown that the substantive factors are $0.71 \%$, whereas the average method factor is only $0.20 \%$ of the variance, suggesting that there is no possibility of CMV in this research. Second, the findings of Table 3 state that all inter-correlation scores are less than 0.90 (Pavlou \& El Sawy, 2006; Pitafi, Kanwal, \& Khan, 2020), which is proof of the non-existence of CMV in the dataset. Therefore, based on both these evaluations, we can claim that CMV is not a serious problem in the present study.

\subsection{Structural model and hypotheses testing}

The AMOS 21 software was used to explore the effect of socio-cultural activities on the subjective well-being of citizens in the framework of CPEC. The suggested research model was evaluated using a structural equation method with an estimation of maximum likelihood (ML) (J. Hair et al., 2017). The results of structural model shown $(\mathrm{CFI}=0.948, \mathrm{TLI}=0.941, \mathrm{IFI}=0.948, \mathrm{NFI}=0.911$, AGFI $=0.894$, $\mathrm{REMSA}=0.05, \mathrm{CMIN} / \mathrm{DF}=612.60 / 268=2.28)$ that all the values are within a range (J. Hair et al., 2017). In the structural model, the link between constructs independent variables and dependent variables was evaluated using structural equation techniques as shown in Figure 1. Results have shown that all control variables are insignificant.

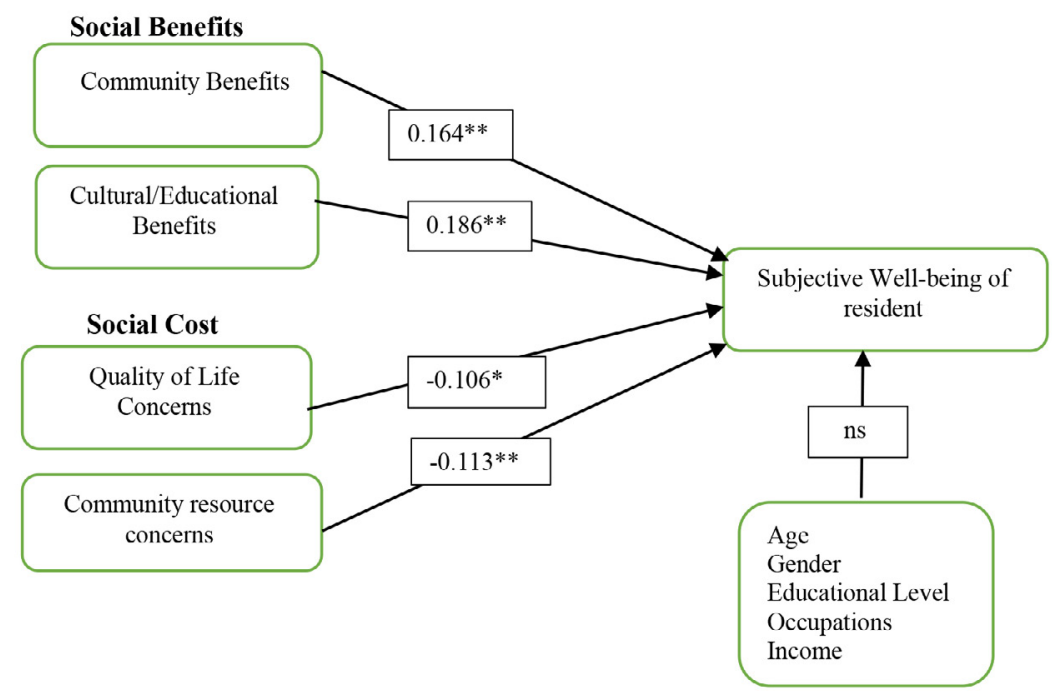

Figure 2. Research model Note: ${ }^{*} \mathrm{p}<0.05,{ }^{* *} \mathrm{p}<0.01$.

The results of all the hypotheses studied are shown in Table 4 . Table 4 findings indicate that the connection between community benefits with developments of CPEC and subjective well-being was 
positive with $(\mathrm{B}=0.164, \mathrm{t}=3.688, \mathrm{p}<0.01)$ thereby supporting Hypothesis 1 . Hypothesis 2 suggested that the educational/cultural benefits of citizens with the development of CPEC should be positively linked to the subjective well-being of inhabitants. Table 4 shows that the educational/cultural benefits of residents have a positive effect on the subjective well-being of residents with $(B=0.186, t=4.914$, $\mathrm{p}<0.01)$. Therefore, Hypothesis 2 is validated by the current study. We proposed a link between the QOL concerns and the well-being of the local community in Hypothesis 3. As shown in Table 4 that the coefficient and $\mathrm{t}$-values were significant $(\mathrm{B}=-0.106, \mathrm{t}=-2.211, \mathrm{p}<0.05)$, thereby validating Hypothesis 3. In addition, Hypothesis 4 examined the link between community resource concerns and the well-being of the community. The findings of Hypothesis 4 suggested the significant link between community concerns and well-being with $(B=-0.113, t=-2.526, \mathrm{p}<0.01)$, Hypothesis 4 is validated.

Table 4. Hypothesis testing

\begin{tabular}{|c|c|c|c|c|}
\hline Relationship & B & SE & $\mathbf{t}$ & Results \\
\hline $\begin{array}{l}\text { Community benefit to Subjective well-being of } \\
\text { Residence }\end{array}$ & 0.164 & 0.036 & $3.688^{* *}$ & Supported \\
\hline $\begin{array}{l}\text { Cultural/educational benefits to Subjective well- } \\
\text { being of Residence }\end{array}$ & 0.186 & 0.037 & $4.914^{* *}$ & $======$ \\
\hline $\begin{array}{l}\text { Quality of Life Concern to Subjective well-being } \\
\text { of Residence }\end{array}$ & -0.106 & 0.028 & $-2.211^{*}$ & $======$ \\
\hline $\begin{array}{l}\text { Community Resource Concerns to Subjective } \\
\text { well-being of Residence }\end{array}$ & -0.113 & 0.033 & $-2.526^{* *}$ & $======$ \\
\hline Occupation to Subjective well-being of Residence & 0.03 & 0.02 & 1.34 & Insignificant \\
\hline Income to Subjective well-being of Residence & -0.03 & 0.02 & -1.24 & $======$ \\
\hline $\begin{array}{l}\text { Education level to Subjective well-being of Resi- } \\
\text { dence }\end{array}$ & -0.06 & 0.04 & -0.14 & $======$ \\
\hline Age to Subjective well-being of Residence & -0.05 & 0.03 & -1.67 & $======$ \\
\hline Gender to Subjective well-being of Residence & -0.07 & 0.05 & -1.21 & $======$ \\
\hline
\end{tabular}

Note: ${ }^{*} \mathrm{p}<0.05,{ }^{* *} \mathrm{p}<0.01$

\section{Discussion, implication, limitations}

\subsection{Discussion}

The goal of the present study was to examine the socio-cultural impact of the development of the CPEC project in Pakistan on the well-being of citizens. The CPEC project is still at an early stage of development, with policymakers stating that this project will change the fortunes of the entire region. In addition, the socio-cultural effects of CPEC development have not been explored by prior scholars. To tackle this research gap, the present study explored the well-being of citizens in the framework of CPEC development. Using the primary data obtained from Baluchistan, Pakistan, this research gives very exciting outcomes. The connection between the social cost, benefits, and well-being of citizens has been explored in the framework of the CPEC development project. The findings of the present research support all the suggested hypotheses. Specifically, the relationship between community benefits with developments of CPEC and community's well-being was found significant, which is according to our suppositions. These results are consistent with previous studies (Khetran, 2016; Raza, Mohiuddin, Zaidi, \& Osama, 2018; Tehsin, Khan, \& Sargana, 2017), these studies highlighted the benefits of CPEC projects for lo- 
cal communities. For example, Kanwal et al. (2019a) reported that local communities can set up small and large businesses along CPEC routes, such as small industries, restaurants, motor shops, and other small stores. Development of CPEC will also bring cultural/educational benefits to the local society. The link between cultural/educational benefits and well-being was also found positive, which supported the arguments that have been mentioned by previous studies. Previously, scholars asserted that road and transport have an important connection with community education (Ali et al., 2017; Kanwal et al., 2019a; Smith, 2001). For example, Smith (2001) noted that children's education is considerably linked to travel time and distance. Similarly, Kanwal et al. (2019a) discovered that the primary factors of poor literacy rate in remote regions were the inaccessibility of educational institutions. In addition, QOL concerns showed a negative relationship with well-being of residents. Community resource concern showed the negative relationship with well-being, which supports our arguments. Past studies also found a significant relationship between residents' QOL and well-being (Yolal et al., 2016).

\subsection{Implications}

The results of this study have made several theoretical and practical contributions. First, we evaluated the underlying connection between the local community's perception of socio-cultural issues and their well-being in the framework of CPEC development. Local inhabitant's well-being was explored as an outcome variable in this study. In reality, the construction of CPEC infrastructure not only benefited the local society economically but also provided socio-cultural advantages, there is no research survey which examined the socio-cultural effect on the well-being of citizens in the framework of CPEC. Second, the results of this research stated that policymakers should consider both economic and non-economic measures in assessing the well-being of citizens, as both are equally contributing to the well-being of citizens.

Thirdly, the uniqueness of this research is that we conducted this survey in Gwadar Baluchistan. The situation of Baluchistan province is considerably volatile as compared to overall Pakistan in terms of the politically and geographic indicators. Baluchistan province is the backward area of Pakistan in terms of development (Kanwal et al., 2019a), and it is expected that CPEC will change the fortunes of the entire province by linking the port of Gwadar to other areas of the country. The results of the present research help officials to think about the cultural effects of developments in CPEC, such as local public asset issues and QOL issues. The Baloch society have also demonstrated/protested many times that some offenders are part of the CPEC project, they think that CPEC is the only route to occupy their rich land.

Fourth, the findings of the present research have shown that the issues about community resources and QOL have a major impact on the well-being of citizens, suggesting that citizens' assets, such as agricultural property, water, port and inappropriate distribution of power, have an impact on the well-being of citizens. These significant results indicated the nature and attitude of the local community towards the CPEC development. These results may also assist officials of CPEC to understand resident's suspects and compensate them equally in terms of employment, business, and education. The Government of Pakistan should grant interest-free loans to the local population to start a business or build houses to foster a goodwill gesture towards the community. These social benefits may motivate the local community and may also increase the well-being of local inhabitants.

Finally, it is suggested that policymakers develop better policies and schemes to promote CPEC development, as this research offers empirical support that can connect perceived benefits from CPEC to citizens' QOL, resource concerns, and well-being. Officials of CPEC also should identify the factors which are related to local community well-being and develop some strategies to manage and monitor these factors. The Government of Pakistan should compensate the local population and provide employment opportunities and business possibilities, since for the development of CPEC local society is 
very much influenced, such as moving of homes from one location to another. Chinese Government official should also communicate directly with local inhabitants and provide business opportunities to the local Balouch community in CPEC development project to ensure community engagement.

\subsection{Limitations}

The findings of this research should be assessed against certain limitations. First, this study examined the impact of community perceptions of social cost and benefits of CPEC infrastructure development on their well-being. Residents' well-being may be affected by other variables, such as jobs, business and community participation, which should to theoretical for future studies.

Second, the present research is based on inhabitants of Gwadar City of Baluchistan Province Pakistan, although the selection of a sample from Gwadar Province is good for this research, as policymakers argue that the main beneficiary of CPEC development are resident of Baluchistan. Nevertheless, there are some political problems in the province of Baluchistan, and the local population is already opposed to foreign investment in the region. CPEC development project is already operationalized in all over Pakistan (Kanwal et al., 2019a). Future researchers may use the same conceptual model and undertake the same type of study in other areas of Pakistan such as Karachi, in the Sindh province of Pakistan. Scholars may also cover the local business society and examine the perception of the local business society towards development of CPEC.

Third, the present research evaluated QOL as a social cost and an independent variable, future scholars may consider QOL as a dependent variable using another parameter. It will be more interesting, to investigate the QOL of local inhabitants with the construction of the CPEC project.

Fourth, the CPEC route crosses the Gilgit-Baltistan region of Pakistan, which is close to the Indian border. The Indian Government is also showing great graveness towards this route. The Indian authority asserted that a terrorist attack would increase with the construction of the CPEC route (S. Ali, 2015; Kanwal, Chong, et al., 2019b; Ranjan, 2015). In addition, the Indian government believes that CPEC is just a cover of the actual intent of the Chinese government to increase its influence in the sub-continent region. Pakistan will be economically strengthened with the construction of CPEC route, Pakistan could then be able to put Kashmir issue on the foreign policy agenda, for resolution that has been long overdue and international community has turned a blind eye towards the atrocities of the Indian Government in the region (Wagner, 2016). Therefore, scholars are advised to conduct a research study that addresses the Indian graveness related to CPEC route.

Finally, it is suggested that CPEC officials stress the advantages of the CPEC project by organizing public conferences, corner meetings with the local community. As many of these areas are considered to be tribal areas where a close network of communities keeps to themselves and have a town elder for decisions, corner meetings can be of good use to give a positive spin to the benefits of CPEC. Policymakers can also use social media applications or television/social media to advertise the benefits of CPEC projects with the local community. When the local community realizes the benefits of the CPEC project, their attitude will be favorable and that will provide more support for its subsequent development and sustainability.

\section{Conclusion}

The Current study looked at the socio-cultural effects on the well-being of citizens in the framework of CPEC development. The findings of this research are based on our expectations and are linked to several 
previous research (Ali et al., 2017; Kanwal, Pitafi, Rasheed, et al., 2019; Yoon, Gursoy, \& Chen, 2001). Specifically, the findings suggested an important connection between the educational /social benefits and well-being of residents. It is recognized that the construction of infrastructure under the title of CPEC offers social interaction and educational opportunities for inhabitants by linking distant regions. In addition, community QOL issues such as traffic congestion, accidents, noise that increase with the development of CPEC may have a major adverse impact on the well-being of society. Community asset issues have also been identified as having an adverse impact on the well-being of the community. The development of CPEC, community resources, such as agricultural property, shifting of homes and destruction or damage to historic sites, such as high mountains, may be affected. This study puts new light on the well-being of local communities in the framework of CPEC. The findings may help decisionmakers and CPEC officials to develop potential measures that are related to the development of CPEC infrastructure while giving due consideration to the local community.

\section{Acknowledgements}

The work described in this paper was supported by the National Natural Science Foundation of China (NSFC: 71531008, 71521001, and 71490720), Tianjin Philosophy and Science Planning (Project no, TJYYQN19-004); the Fundamental Research Funds for the Central Universities (JZ2020HGQB0217). 


\section{References}

Ahmad, R., \& Hong, M. (2017). China-Pakistan economic corridor and its social implication for Pakistan: How will CPEC boost Pakistan's infrastructures and overcome the challenges? Arts and Social Sciences Journal, 8(2), 265.

Ali, L., Mi, J., Shah, M., Khan, A., \& Imran, M. (2017). Transport culture akin to the China-Pakistan economic corridor. Human Systems Management, 36(4), 381-396.

Ali, S. (2015). Importance and implications of CPEC in South Asia: The Indian factor. Journal of Indian Studies, 1(1), 21-36.

Asomani-Boateng, R., Fricano, R. J., \& Adarkwa, F. (2015). Assessing the socio-economic impacts of rural road improvements in Ghana: A case study of transport sector program support (II). Case Studies on Transport Policy, 3(4), 355-366.

Barrios, E. B. (2008). Infrastructure and rural development: Household perceptions on rural development. Progress in Planning, 70(1), 1-44.

Boschini, A., Dreber, A., von Essen, E., Muren, A., \& Ranehill, E. (2018). Gender, risk preferences and willingness to compete in a random sample of the Swedish population. Journal of Behavioral and Experimental Economics, 83(C). https://doi.org/10.1016/j.socec.2019.101467

Chaum, D. (2019). Random sample elections: Google patents.

Chen, Y., Lehto, X. Y., \& Cai, L. (2013). Vacation and well-being: A study of Chinese tourists. Annals of Tourism Research, 42, 284-310.

Cohen, J., Cohen, P., West, S. G., \& Aiken, L. S. (2013). Applied multiple regression/correlation analysis for the behavioral sciences. London: Routledge.

Cohen, S. (2004). Social relationships and health. American Psychologist, 59(8), 676.

Daldeniz, B., \& Hampton, M. P. (2013). Dive tourism and local communities: Active participation or subject to impacts? Case studies from Malaysia. International Journal of Tourism Research, 15(5), 507-520.

Delamere, T. A., Wankel, L. M., \& Hinch, T. D. (2001). Development of a scale to measure resident attitudes toward the social impacts of community festivals, Part I: Item generation and purification of the measure. Event Management, 7(1), 11-24.

Diener, E., Oishi, S., \& Lucas, R. E. (2003). Personality, culture, and subjective well-being: Emotional and cognitive evaluations of life. Annual Review of Psychology, 54(1), 403-425.

Diener, E., \& Suh, E. (1997). Measuring quality of life: Economic, social, and subjective indicators. Social Indicators Research, 40(1-2), 189-216.

Fornell, C., \& Larcker, D. F. (1981). Evaluating structural equation models with unobservable variables and measurement error. Journal of Marketing Research, 18, 39-50.

Hair, J., Hollingsworth, C. L., Randolph, A. B., \& Chong, A. Y. L. (2017). An updated and expanded assessment of PLS-SEM in information systems research. Industrial Management \& Data Systems, $117(3), 442-458$.

Hair, J. F., Ringle, C. M., \& Sarstedt, M. (2011). PLS-SEM: Indeed a silver bullet. Journal of Marketing Theory and Practice, 19(2), 139-152.

Haq, R., \& Farooq, N. (2016). Impact of CPEC on social welfare in Pakistan: A district level analysis. Paper presented at the Proceedings of the 32nd Annual General Meeting and Conference, Pakistan Society of Development Economics, Pakistan Institute of Development Economics, Islamabad, Pakistan.

Hinkin, T. R. (1998). A brief tutorial on the development of measures for use in survey questionnaires. Organizational Research Methods, 1(1), 104-121.

Hussain, A. (2017). Knowledge Based Approach to CPEC. 
Kanwal, S., Chong, R., \& Pitafi, A. H. (2019a). China-Pakistan economic corridor projects development in Pakistan: Local citizens benefits perspective. Journal of Public Affairs, 19(1), 12.

Kanwal, S., Chong, R., \& Pitafi, A. H. (2019b). Support for China-Pakistan economic corridor development in Pakistan: A local community perspective using the social exchange theory. Journal of Public Affairs, 19(2), 12.

Kanwal, S., Pitafi, A. H., Ahmad, M., Khan, N. A., Ali, S. M., \& Surahio, M. K. (2019). Cross-border analysis of China-Pakistan economic corridor development project and local residence quality of life. Journal of Public Affairs, 20(2), e2022.

Kanwal, S., Pitafi, A. H., Malik, M. Y., Khan, N. A., \& Rashid, R. M. (2020). Local Pakistani Citizens' Benefits and Attitudes Toward China-Pakistan Economic Corridor Projects. SAGE Open, 10(3), 2158244020942759.

Kanwal, S., Pitafi, A. H., Pitafi, A., Nadeem, M. A., Younis, A., \& Chong, R. (2019). China-Pakistan economic corridor (CPEC) development projects and entrepreneurial potential of locals. Journal of Public Affairs, 19(2), e1954.

Kanwal, S., Pitafi, A. H., Rasheed, M. I., Pitafi, A., \& Iqbal, J. (2019). Assessment of residents' perceptions and support toward development projects: A study of the China-Pakistan economic corridor. The Social Science Journal, 57, 1-17.

Kanwal, S., Rasheed, M. I., Pitafi, A. H., Pitafi, A., \& Ren, M. (2020). Road and transport infrastructure development and community support for tourism: The role of perceived benefits, and community satisfaction. Tourism Management, 77, 104014.

Khetran, M. S. (2016). CPEC: Benefits for Balochistan: Retrieved from (ISSI issue brief): http://issi. org.pk/wp-content/uploads

Kim, K., Uysal, M., \& Sirgy, M. J. (2013). How does tourism in a community impact the quality of life of community residents? Tourism Management, 36, 527-540.

Liang, H., Saraf, N., Hu, Q., \& Xue, Y. (2007). Assimilation of enterprise systems: the effect of institutional pressures and the mediating role of top management. MIS Quarterly, 31(1)59-87.

Liu, H., Ke, W., Wei, K. K., \& Hua, Z. (2013). The impact of IT capabilities on firm performance: The mediating roles of absorptive capacity and supply chain agility. Decision Support Systems, 54(3), 1452-1462. https://doi.org/10.1016/j.dss.2012.12.016

Masson, S., \& Petiot, R. (2009). Can the high speed rail reinforce tourism attractiveness? The case of the high speed rail between Perpignan (France) and Barcelona (Spain). Technovation, 29(9), 611-617.

Mattson, J. (2011). Transportation, distance, and health care utilization for older adults in rural and small urban areas. Transportation Research Record, 2265(1), 192-199.

McGillivray, M., \& Clarke, M. (2006). Human well-being: Concepts and measures. In Understanding human well-being (pp. 3-16) Tokyo: UNU Press.

Naidoo, P., \& Pearce, P. L. (2018). Enclave tourism versus agritourism: The economic debate. Current Issues in Tourism, 21(17), 1946-1965.

Nawijn, J., \& Mitas, O. (2012). Resident attitudes to tourism and their effect on subjective well-being: The case of Palma de Mallorca. Journal of Travel Research, 51(5), 531-541.

Nunkoo, R., \& Gursoy, D. (2016). Rethinking the role of power and trust in tourism planning. Journal of Hospitality Marketing \& Management, 25(4), 512-522.

Nunnally, J. C., \& Bernstein, I. (1978). Psychometric theory. (2nd edition).New York: McGraw-Hill.

Pappas, N. (2014). Hosting mega events: Londoners' support of the 2012 Olympics. Journal of Hospitality and Tourism Management, 21, 10-17.

Pavlou, P. A., \& El Sawy, O. A. (2006). From IT leveraging competence to competitive advantage in turbulent environments: The case of new product development. Information Systems Research, 17(3), 
$198-227$.

Pitafi, A. H., Kanwal, S., Alii, A., Khan, A. N., \& Ameen, W. (2018). Moderating roles of IT competency and work cooperation on employee work performance in an ESM environment. Technology in Society, 55, 199-208.

Pitafi, A. H., Kanwal, S., \& Khan, A. N. (2020). Effects of perceived ease of use on SNSs-addiction through psychological dependence, habit: The moderating role of perceived usefulness. International Journal of Business Information Systems, 33(3), 383-407.

Pitafi, A. H., Kanwal, S., \& Pitafi, A. (2019). Effect of enterprise social media and psychological safety on employee's agility: Mediating role of communication quality. International Journal of Agile Systems and Management, 12(1), 1-26.

Pitafi, A. H., Khan, A. N., Khan, N. A., \& Ren, M. (2020). Using enterprise social media to investigate the effect of workplace conflict on employee creativity. In Telematics and Informatics. Amsterdam: Elsevier Science.

Pitafi, A. H., Liu, H., \& Cai, Z. (2018). Investigating the relationship between workplace conflict and employee agility: The role of enterprise social media. Telematics and Informatics, 35(8), 2157-2172.

Pitafi, A. H., Rasheed, M. I., Kanwal, S., \& Ren, M. (2020). Employee agility and enterprise social media: Role of IT proficiency and work expertise. Technology in Society, 63, 101333. https://doi. org/10.1016/j.techsoc.2020.101333

Quinn, B. (2006). Problematising 'festival tourism': Arts festivals and sustainable development in Ireland. Journal of Sustainable Tourism, 14(3), 288-306.

Ranjan, A. (2015). The China-Pakistan economic corridor: India's options. Delhi: Institute of Chinese Studies.

Raza, H., Mohiuddin, Z. A., Zaidi, S. S. Z., \& Osama, A. (2018). CPEC: Pakistan-China cordial tiesa boost to Pakistan's economy. Journal of Accounting, Business and Finance Research, 2(1), 1-6.

Rehman, A. U., Hakim, A., Khan, K., \& Khan, I. U. (2018). Role of CPEC in development of trade, transport and economy of Pakistan. Romanian Journal of Transport Infrastructure, 7(1), 77-92.

Richards, G., \& Wilson, J. (2004). The impact of cultural events on city image: Rotterdam, cultural capital of Europe 2001. Urban Studies, 41(10), 1931-1951.

Ryan, R. M., \& Frederick, C. (1997). On energy, personality, and health: Subjective vitality as a dynamic reflection of well-being. Journal of Personality, 65(3), 529-565.

Shaikh, F., Ji, Q., \& Fan, Y. (2016). Prospects of Pakistan-China energy and economic corridor. Renewable and Sustainable Energy Reviews, 59, 253-263.

Sirgy, M. J., Rahtz, D. R., Cicic, M., \& Underwood, R. (2000). A method for assessing residents' satisfaction with community-based services: A quality-of-life perspective. Social Indicators Research, 49(3), 279-316.

Smith, J. H. (2001). Education foundations: Changing public education and the way Connecticut communities pay for it. CPEC Best Practices Report, 2(1).

Tehsin, M., Khan, A. A., \& Sargana, T.-u.-H. (2017). CPEC and sustainable economic growth for Pakistan. Pakistan Vision, 18(2), 102-118.

Wagner, C. (2016). The effects of the China-Pakistan economic corridor on India-Pakistan relations. Retrieved from https://nbn-resolving.org/urn:nbn:de:0168-ssoar-46898-4

Wei, C., Pitafi, A. H., Kanwal, S., Ali, A., \& Ren, M. (2020). Improving employee agility using enterprise social media and digital fluency: Moderated mediation model. IEEE Acesss, 8, 68799-68810.

Wolf, S. O. (2018). China-Pakistan economic corridor (CPEC): Regional cooperation in the wider South Asian region. In China's global rebalancing and the new silk road (pp. 85-100). New York: Springer. 
Woo, E., Kim, H., \& Uysal, M. (2015). Life satisfaction and support for tourism development. Annals of Tourism Research, 50, 84-97.

Yolal, M., Gursoy, D., Uysal, M., Kim, H. L., \& Karacaoğlu, S. (2016). Impacts of festivals and events on residents' well-being. Annals of Tourism Research, 61, 1-18.

Yoon, Y., Gursoy, D., \& Chen, J. S. (2001). Validating a tourism development theory with structural equation modeling. Tourism Management, 22(4), 363-372. 